\title{
O IMPERATIVO DA CULTURA DIGITAL: ENTRE NOVAS TECNOLOGIAS E ESTUDOS CULTURAIS
}

SANDRO FACCIN BORTOLAZZO UNIVERSIDADE FEDERAL DO RIO GRANDE DO SU PORTO ALEGRE, RIO GRANDE DO SUL, BRASIL E-MAIL: SANDROBORTOLAZZO@HOTMAIL.COM

HTTP://DX.DOI.ORG/10.5902/2316882X22133 


\title{
O IMPERATIVO DA CULTURA DIGITAL: \\ ENTRE NOVAS TECNOLOGIAS E ESTUDOS CULTURAIS
}

Resumo: o artigo investiga a produção de uma Cultura Digital atuando como imperativa e articula conceitos que envolvem comunicação e tecnologias. Esta investigação chama atenção para a presença de um regime tecnológico digital considerado imperativo e, muitas vezes, indispensável. Os achados do estudo apontam também para uma Cultura Digital que invade os diversos espaços de sociabilidade, instituindo a integração das tecnologias às diversas atividades cotidianas.

Palavras chave: Cultura Digital; Tecnologias Digitais; Estudos Culturais.

\section{EL IMPERATIVO DE LA CULTURA DIGITAL: \\ ENTRE LAS NUEVAS TECNOLOGÍAS Y LOS ESTUDIOS CULTURALES}

Resumen: el artigo investiga la producción de una cultura digital que actúa como imperativa y articula conceptos que se relacionan con la comunicación y las tecnologías. Esta investigación pone en relieve la presencia de un régimen tecnológico digital considerado imprescindible e indispensable. Los hallazgos del estudio también apuntan una cultura digital que invade los diferentes espacios de sociabilidad, forjando e instituyendo la integración de las tecnologías en las diversas actividades diarias.

Palabras Clave: Cultura Digital; Tecnologias Digitales; Estudios Culturales.

THE IMPERATIVE OF DIGITAL CULTURE

BETWEEN NEW TECHNOLOGIES AND CULTURAL STUDIES

\begin{abstract}
Digital Culture acting as imperative and articulates concepts involving communication and technologies. This research draws attention to the presence of a digital technological regime considered imperative and indispensable. The study findings also point to a Digital Culture that invades the different spaces of sociability, forging and instituting the integration of technologies into daily activities.
\end{abstract}

Keywords: Digital Culture; Digital Technologies; Cultural Studies. 


\section{INTRODUÇÃO}

Por quantos artefatos digitais você se encontra rodeado? Um, dois, três, quatro. Não se esqueça de contar o Ipad, o Ipod, o computador, o smartphone, o videogame do filho (a) e o seu também. Caso não forem muitos os aparelhos, pode ser que neste exato momento o seu telefone celular toque, vibre, informe a chegada de mensagem de texto, anuncie o aniversário de um amigo (a) ou um simples alerta de que a bateria chegou ao fim. Talvez você esteja cansado (a) e precise dormir. Mas, por impulso, você acessa à internet (via celular, computador, entre outros artefatos) e percebe que um amigo (a) está chamando para conversar no Facebook e concomitantemente outro chama pelo whatsApp.

As relações que se mantêm com artefatos digitais tais como telefones celulares e tablets têm se configurado como elementos significativos nas transformações sociais e culturais vividas na contemporaneidade. Assim, quando uma série de invenções tecnológicas permitiu a conexão entre milhões de pessoas às redes de informações, as práticas cotidianas passaram também a incorporar certos hábitos gerados pelo uso intenso das tecnologias.

O horizonte teórico de movimentação deste trabalho se inspira na vertente pós-estruturalista dos Estudos Culturais. O pós-estruturalismo rejeita a ideia de estruturas estáveis que conferem significados a partir de binarismos e instaura teorias desconstrutivistas em que os textos, as imagens, a música, o cinema, vêm sendo "libertados" a uma pluralidade de sentidos. Segundo a perspectiva pós-estruturalista, os significados são instáveis, negociáveis, estão sempre em processo, e a realidade seria considerada uma construção social, histórica e subjetiva. Dessa forma, parte-se da ideia de que o uso e a apropriação das tecnologias digitais são produções culturais de determinada sociedade, pontuadas pelo caráter histórico e contingente.

A proposta deste artigo está centrada na investigação da manifestação de uma Cultura Digital atuando como imperativa. Além disso, articula algumas noções centrais nas pesquisas que envolvem comunicação e tecnologias: Mídia Digital, Novas Tecnologias de Comunicação e Informação e Cultura Digital. Ao propor este tipo de investigação, pretende-se chamar atenção para a presença de um regime tecnológico inscrito em vários lugares de sociabilidade e considerado, repetidas vezes, indispensável.

Rev. Cad.Comun, Santa Maria, v.20,n.1, art 1, p.1 de 24, jan/abr.2016 
O referencial teórico tem como base autores que discutem os conceitos de Cultura, Novas Tecnologias e Cultura Digital, com destaque à Williams (1969), Lister et.al (2009), Gere (2008), entre outros. A pesquisa apresenta dois movimentos de investigação interligados. O primeiro movimento exibe um breve panorama dos conceitos de mídia e novas tecnologias, com ênfase nas práticas sociais desenvolvidas a partir do digital, dos computadores em rede e das formas como as tecnologias digitais alteraram outros meios. O segundo movimento discute questões referentes ao determinismo tecnológico e às novas mídias, arriscando uma problematização sobre o conceito de Cultura Digital.

\section{ENTRE MÍDIAS E NOVAS TECNOLOGIAS}

A palavra "mídia" tem sido utilizada no mesmo sentido que imprensa, jornalismo, meio de comunicação, veículo. No plural, "mídias", também vêm sendo citada, simplesmente abandonando, por deliberação ou não, sua origem latina como plural de médium (meio). No sentido amplo da palavra, as falas, os gestos, as expressões faciais, as vestimentas e a dança, por exemplo, igualmente podem ser analisadas enquanto mídias. Geralmente quando se estuda mídia, há uma analogia direta aos meios de comunicação e às instituições especializadas onde os profissionais da área trabalham: a mídia impressa, a mídia televisiva, a publicidade, o cinema, a fotografia, e assim por diante. A expressão "mídia" também se refere aos produtos culturais e materiais dessas mesmas instituições, a exemplo dos distintos gêneros de notícias, dos filmes, das novelas, dos livros, dos discos, etc.

É possível continuar pensando a mídia nas formas descritas anteriormente, no entanto, em vista de um cenário esboçado por mudanças efêmeras e contínuas, as categorias assumidas são constantemente desafiadas. Um exemplo é a transmedia, em que migrações de conteúdos e de propriedade intelectual ocorrem através de vários meios, forçando os produtores a colaborar uns com os outros. Outro exemplo é a hipermídia - conjunto de meios que permite o acesso simultâneo a textos, sons e imagens de uma maneira interativa, e no qual os usuários podem controlar a navegação.

Rev. Cad.Comun, Santa Maria, v.20,n.1, art 1, p.1 de 24, jan/abr.2016 
Expressões tais como "Novas Mídias", "Novas Tecnologias de Informação e Comunicação", “Mídia Digital”, "Cultural Digital” - entres outros termos que conectam comunicação, mídia, sociedade, cultura e tecnologias - têm sido empregadas nas reportagens midiáticas, nos textos acadêmicos, na publicidade de vários produtos e no vocabulário cotidiano. Contudo, discutir essas expressões, inevitavelmente, gera inúmeros questionamentos. A começar pela qualificação "nova". O "novo" carrega historicamente uma marca ideológica que significa, continuamente, algo meIhor. O novo está associado com a vanguarda, com certa visão, na maioria das vezes, positiva, do futuro. Junto às Novas Mídias e às Novas Tecnologias de Comunicação e Informação emergem a utopia de maior produtividade e das oportunidades e possibilidades comunicacionais, educacionais, publicitárias, entre outras. Para além das discussões sobre o novo, o que de fato se constitui como novidade nos meios de comunicação?

De acordo com Lister et al. (2009), a expressão "Novas Mídias" emergiu para capturar certa sensação de que, em passo acelerado, a partir dos anos 1980, o universo dos meios de comunicação começou a se mostrar diferente. Esse foi o caso da televisão, da fotografia e da mídia impressa que, gradualmente, estiveram envolvidas em um fluxo constante e contínuo de mudanças culturais, institucionais e, principalmente, tecnológicas. Para Lister et al. (2009), alguns indicativos dessas mudanças competem à passagem da modernidade para a pós-modernidade, aos processos de globalização e à substituição de uma era industrial de manufatura por uma era da informação. Mesmo assim, até que ponto é possível identificar algum tipo de mudança significativa que se encontre subjacente aos novos meios de comunicação, quer dizer, algo mais tangível que ultrapasse a discussão sobre as mudanças de contextos? Neste sentido é que reside a expressão “Mídia Digital”, uma vez que leva em consideração um meio específico, o digital, e suas implicações em função do registro, da produção, do armazenamento, do consumo e da distribuição de informações.

Na perspectiva de Lemos (2003), o que chamamos de Novas Tecnologias de Comunicação e Informação surgem a partir do ano de 1975, quando dá fusão das telecomunicações analógicas com a informática, o que possibilitou a veiculação sob um mesmo suporte, o computador. Segundo Lemos (2003), essa revolução implica a passagem dos mass media (TV, imprensa e cinema) para formas individualizadas de produção e estoque de informação.

Rev. Cad.Comun, Santa Maria, v.20,n.1, art 1, p.1 de 24, jan/abr.2016 
Com as tecnologias analógicas, a transmissão, o armazenamento e a recuperação de informação eram completamente inflexíveis. Com o digital, a forma de distribuição e armazenamento são independentes, multimodais, onde a escolha em obter uma informação sob a forma textual, imagética ou sonora é independente do modo pelo qual ela é transmitida. Nesse sentido, as redes eletrônicas constituem uma nova forma de publicação (a eletrônica), onde os computadores podem produzir cópias tão perfeitas quanto o original (LEMOS, 2003, p.70).

Interessante nessa discussão é que não há uma mudança radical que dividiu o mundo da comunicação entre as velhas e as novas mídias, ou melhor, entre as mídias analógicas e as mídias digitais. Isso porque a distribuição das informações em rede, por exemplo, não existiria sem a "espinha tecnológica" fornecida pelas então existentes formas de transmissão, dos telefones aos rádios. Seguindo as orientações de Lister et al. (2009), o termo "Novas Mídias" pode ser analisado se referindo, então, às novas experiências textuais, aos novos modos de representar o mundo e às novas relações dos sujeitos (usuários e consumidores) com as tecnologias midiáticas.

Muitas das abordagens críticas simplesmente negam que tenha ocorrido qualquer tipo substancial de mudança, seja nas mídias, seja no contexto cultural em que estão inseridas. Por outro lado, é preciso considerar também aquelas vozes que enxergam as tecnologias e as mídias digitais como sendo a própria utopia. Dessa forma, para corroborar o debate, volta-se a dois teóricos: Marshall McLuhan e Raymond Williams. Embora eles tenham deixado seus legados no momento em que os computadores pessoais estavam prestes a se proliferar e ganhar os mercados (tanto Williams quanto McLuhan desenvolveram seus trabalhos nas décadas de 1960 e 1970), as análises dos dois autores continuam repercutindo entre os teóricos da contemporaneidade. Nos argumentos de ambos se debruçam e ecoam ainda múltiplos significados sobre o papel das tecnologias na vida em sociedade. As premissas dos autores marcam o tom polarizado da discussão contemporânea, tendo de um lado os seguidores de McLuhan que enxergam as novas tecnologias como revolucionárias, e do outro os que seguem uma linha mais próxima de Williams, considerando as tecnologias como parte de processos sociais e culturais mais amplos.

De acordo com Lister et al. (2009), McLuhan estava interessado em identificar e explorar o que ele percebia como grandes mudanças cultu-

Rev. Cad.Comun, Santa Maria, v.20,n.1, art 1, p.1 de 24, jan/abr.2016 
rais trazidas pelas tecnologias midiáticas, enquanto Williams estava mais voltado às condições de possibilidade para o surgimento dessas novas mídias. McLuhan tinha preocupações com os efeitos culturais das novas tecnologias, já Williams procurou mostrar que não há nada novo em uma determinada tecnologia que possa garantir certos efeitos culturais ou sociais (LISTER et al.,2009).

As teses de McLuhan procuram explicar todos os fenômenos, desde a primeira produção comunicativa registrada entre seres humanos, como deterministas, no sentido de depender de somente um fator dominante - neste caso, a tecnologia. Na contramão das propostas de McLuhan está a de que as tecnologias não são nada até que sejam dadas a elas determinado significado cultural, ou melhor, importa o que os sujeitos fazem com as tecnologias e não o contrário. Assim, em Williams, as tecnologias estão envolvidas em processos que McLuhan simplesmente descarta. Quer dizer, as tecnologias não podem estar apartadas das questões práticas; elas emergem do próprio agenciamento e das intenções humanas. $\mathrm{E}$ tais intenções surgem para atender desejos e interesses históricos e culturalmente específicos (WILLIAMS, 1975).

Seguindo novamente as análises propostas por Lister et al. (2009), Williams não se contenta em compreender as tecnologias apenas como artefatos, uma vez que, na sua apreensão, os conhecimentos e as competências necessárias e adquiridas para utilizar uma ferramenta ou uma máquina são parte integrante de qualquer processo conceitual que pretenda definir o que é uma tecnologia e seus usos.

Lister et al. (2009) comentam que, nos estudos de mídia e também nos Estudos Culturais, o elemento tecnológico tem sido fortemente qualificado: ora celebrado, ora tomando formas resistentes. Parte dessa visão tem origem numa série de ensaios de Williams (1975) que se tornaram os principais argumentos contra McLuhan em reação a qualquer tipo de determinismo tecnológico. Na perspectiva de Lister et al. (2009), McLuhan é uma figura controversa que inicialmente foi desacreditado por seus pronunciamentos insustentáveis. A obra de McLuhan tem um apelo significativo para aqueles que creditam às tecnologias grandes e radicais mudanças culturais. Muitas das suas ideias surgiram dentro de uma espécie de "narrativa da redenção", ou seja, grande parte do apelo que McLuhan faz para com as novas tecnologias está na maneira com que ele enxerga a chegada de uma redentora "cultura eletrônica". Para Lister et al. (2009),

Rev. Cad.Comun, Santa Maria, v.20,n.1, art 1, p.1 de 24, jan/abr.2016 
é possível mapear o pensamento de McLuhan a partir de três ideias-chave:

Em primeiro lugar, "remediação", um conceito que atualmente está muito em voga e encontra suas raízes na visão de McLuhan de que "o conteúdo de qualquer meio é sempre outro meio". Em segundo lugar, a ideia de que a mídia e as tecnologias são extensões do corpo humano e dos seus sentidos. Em terceiro lugar, a sua famosa (ou notória) visão de que "o meio é a mensagem” [grifos do autor] (LISTER et al.,2009, p.80).

Remediação é, sem dúvida, um conceito inquestionável tanto para McLuhan quanto para Williams que compartilhavam a ideia de que as novas mídias fazem uma remediação dos conteúdos presentes nas mídias anteriores. Já a ideia das tecnologias como extensões do corpo e do sistema sensorial humano nos impele a reconhecer que essa perspectiva tem sido muito influente, prefigurando o conceito de cyborgue do final do século XX e também o de cibercultura. Para Lister et al. (2009), McLuhan nos alerta também para a dimensão tecnológica das mídias. Ele faz isso recusando qualquer distinção entre mídia e tecnologia. McLuhan (1970) dissipa tecnologias e mídias porque as enxerga como extensões dos sentidos: visão, audição, tato e olfato. Um dos exemplos citados por McLuhan é o da roda que, especialmente, quando passou a funcionar com energia automotiva, transformou radicalmente a experiência de viagens e igualmente de velocidade, assim como também mudou a relação do corpo com o ambiente físico, com o tempo e com o espaço. De fato, essa ampliação do conceito de mídia (meio) alcançando todos os tipos de tecnologias é que permitiu ao autor propagar uma das suas famosas frases: o meio é a mensagem. Para McLuhan (1970), o "meio é a mensagem” não só pelas características do meio que tendem a determinar o tipo de envolvimento que os sujeitos estabelecem, mas porque, em McLuhan, o "meio" é uma extensão do aparelho sensorial humano.

Williams, um dos grandes expoentes dos Estudos Culturais britânicos, foi um dos críticos mais ferozes de McLuhan. McLuhan (1970) defende que as novas tecnologias têm alterado radicalmente as funções físicas e mentais da humanidade de forma geral. Williams (1975) rebate apontando que o que as novas tecnologias arranjam são avanços e práticas já existentes e nos quais determinados grupos sociais enxergam como importantes ou necessárias. As ideias de McLuhan sobre a origem e o avanço das tecnologias são de natureza psicológica e biológica. Na visão de Williams,

Rev. Cad.Comun, Santa Maria, v.20,n.1, art 1, p.1 de 24, jan/abr.2016 
o progresso tecnológico é sociológico. Dessa forma, as tecnologias estariam emergindo a partir do desenvolvimento e da reconfiguração dos recursos tecnológicos já disponíveis em uma determinada cultura. Adiante no debate, Lister et al. (2009) indicam que, para Williams, é o poder que certos grupos sociais possuem que determina o ritmo do desenvolvimento tecnológico.

Outro conceito problemático nessa abordagem é o de "meio". Enquanto McLuhan utiliza o termo "meio" como um tipo de tecnologia, Williams reafirma ser arriscado misturar os dois termos, meio e tecnologia. De fato, é verdade que está implícito no pensamento de Williams (1975) que um meio está atravessado, de alguma maneira, pela utilização específica de uma determinada tecnologia, quer dizer, o meio também se dá pelos usos, pelas intenções e pelos propósitos dessas mesmas tecnologias. No entanto, um meio é mais do que a sua tecnologia. Os meios dependem, também, das práticas.

\section{PROBLEMATIZANDO A CULTURA DIGITAL}

Hoje é difícil imaginar uma sociedade desprovida de televisões, computadores ou redes de telefonia. Os avanços tecnológicos são contínuos, como uma via de mão única, não havendo qualquer possibilidade de retrocesso. Nesta perspectiva, o advento da internet foi um marco na evolução das tecnologias e os progressos de ordem econômica e social ligados à rede, bem como a expansão do consumo de artefatos digitais, têm servido igualmente para moldar muitas das experiências. Na mesma corrente de pensamento, há uma preocupação com os usos culturais das novas tecnologias. E uma questão importante a ser considerada é que as tecnologias não são coadjuvantes em relação às questões culturais, mas elementos centrais. As tecnologias não são acessórios periféricos para os analistas, mas elementos onipresentes. Em suma, "toda a cultura é tecnológica" (LISTER, et al.,2009, p.16).

Para compreender a emergência de uma Cultura Digital como imperativa e tentar posicioná-la como sintoma de uma sociedade que investe fortemente em material tecnológico, é preciso analisar as condições de possibilidade, não somente históricas, mas também econômicas e sociais que permitiram a produção desse tipo de cultura. De fato, é difícil apreender, em toda a sua extensão, as transformações ocasionadas pelo digital.

Rev. Cad.Comun, Santa Maria, v.20,n.1, art 1, p.1 de 24, jan/abr.2016 
A maioria dos meios de comunicação - a televisão, o cinema, a indústria da música, as revistas, os jornais - tem cada vez mais produzido e distribuído seus produtos em formato digital. Mesmo assim, a tecnologia digital não se limita aos meios de comunicação. Computadores com acesso à internet se transformaram em ferramentas indispensáveis a inúmeras atividades do cotidiano - pagamento de contas, transferências bancárias, comunicações instantâneas, compras, entretenimento e lazer, informação, estudo. Nos supermercados, nos bancos, nos shoppings, nos elevadores, nos escritórios, nas escolas, nas universidades, nas estradas e, muitas vezes, nas ruas, somos monitorados digitalmente. Grande parte dos meios pelos quais os governos e outras instituições e organizações atuam, controlam, fiscalizam e punem contam e se apoiam também nas tecnologias digitais.

As transformações sob a égide da tecnologia digital também produziram uma espécie de efeito express em que tudo parece ter um lugar e um ritmo acelerado, alterando igualmente as percepções de espaço e tempo. Segundo Bauman (2001), os fluxos de capital e as pessoas viajam com leveza - apenas com a bagagem de mão, que inclui pasta, telefone celular e um computador portátil. Isso permite aos "passageiros" embarcar e partir de qualquer ponto, sem precisar demorar-se em nenhum lugar além do tempo necessário. Os telefones celulares são exemplos expressivos dessas mutações e acomodações. Antes considerados objetos do mundo corporativo e empresarial, útil à vida de executivos de grandes empresas, hoje sua popularização é inconteste e indispensável à vida dos sujeitos, sejam eles crianças, jovens ou adultos. As versões smartphones estão amplamente disponíveis e, para utilizar uma expressão de Lemos (2009), são uma espécie de "tele tudo", "um dispositivo que é ao mesmo tempo telefone, máquina fotográfica, televisão, cinema, receptor de informações jornalísticas, difusor de e-mails e SMS (...), GPS, tocador de música (MP3 e outros formatos), carteira eletrônica (...)" (idem, p.9).

Recorrer ao digital é evocar, metonimicamente, a todo um conjunto de manifestações que incluem artefatos como tablets e smartphones, simulacros virtuais, comunicações instantâneas, conectividade. É aludir a uma vasta gama de formas midiáticas, possibilitadas pela tecnologia digital, abrangendo a realidade virtual, o cinema digital, a televisão digital, a música eletrônica, os jogos de computador, a internet, a World Wide Web, e assim por diante. Também compreende o mundo dos negócios dominados por empresas de tecnologia como a Microsoft, a Apple ou Sony.

Rev. Cad.Comun, Santa Maria, v.20,n.1, art 1, p.1 de 24, jan/abr.2016 
A partir dessas evidências seria possível propor a existência de uma distinta Cultura Digital, em que o termo digital estaria representando uma forma particular de vida de um grupo ou de grupos de sujeitos em um determinado período da história. Para invocar uma das definições de cultura proposta por Williams (1975), à cultura digital compete pensá-la como um marcador cultural, uma vez que envolveria tanto os artefatos quanto os sistemas de significação e comunicação que demarcam e distinguem nosso modo de vida contemporâneo dos outros.

O debate sobre Cultura Digital, segundo Gere (2008), se apoia em duas crenças interligadas. "Uma delas é a de que tal cultura representa uma decisiva ruptura com aquilo que a precedeu (no caso aqui a cultura analógica), e a outra é a de que a Cultura Digital deriva e é determinada pela existência da tecnologia digital" [grifos nossos] (GERE, 2008, p.17). Mesmo assim, analisar a Cultura Digital como um ente completamente novo, e seu desenvolvimento determinado tão somente pelos avanços tecnológicos, nos remeteria a uma visão, fundamentalmente, determinista. Seria mais adequado sugerir, então, que "a tecnologia digital é um produto da cultura digital, e não vice-versa" (GERE, 2008, p.17). Ou como também sugeriu Gere (2008) ao citar Gilles Deleuze que "a máquina é sempre social antes de ser técnica. Há sempre uma máquina social que seleciona ou atribui os elementos técnicos utilizados" (idem, p.17). Assim, o digital não se refere apenas aos efeitos e possibilidades de uma determinada tecnologia, mas abrange formas de pensar e de desenvolver certas atividades que são incorporadas por essa tecnologia e que permitem a sua existência.

Para Gere (2008), a Cultura Digital é um fenômeno historicamente contingente que emergiu, primeiro, como resposta às exigências do capitalismo moderno e, em seguida, combinada na contestação à guerra. Contudo, a tecnologia digital é apenas uma entre inúmeras fontes que têm contribuído para o desenvolvimento da Cultura Digital. Essas outras incluem, de acordo com Gere (2008), os discursos tecnocientíficos, as práticas artísticas de vanguarda, a utopia da contracultura, a Teórica Crítica e as subculturas como a punk.

De fato, foi no período da Segunda Guerra Mundial que o modelo binário da computação passou a assumir a forma do digital que encontramos no presente. A Segunda Guerra Mundial foi um dos catalisadores não apenas da invenção dos sistemas binários precursores da tecnologia digital dos computadores, mas também do desenvolvimento de uma série de te-

Rev. Cad.Comun, Santa Maria, v.20,n.1, art 1, p.1 de 24, jan/abr.2016 
orias, incluindo a Cibernética, a Teoria da Informação, a Biologia Molecular, a Inteligência Artificial. De acordo com Gere (2008, p. 51), mesmo que em diferentes áreas e contextos, cada um desses sistemas foi influente. "Com efeito, em grande medida, eles representam, coletivamente, o paradigma do pensamento científico e tecnológico do período pós-guerra”. Embora não sendo determinados nem determinantes da invenção e do uso dos computadores, esse conjunto de teorias fazia parte de um mesmo ambiente intelectual.

Um conceito associado à Cultura Digital permite articulações com outros tais como Cibercultura (LEVY, 1999), Era da informação ou Era Digital (CASTELLS, 1999). Cada um deles foi pensado para demarcar esta época em que as relações humanas têm sido fortemente mediadas por artefatos digitais. A Cultura Digital envolveria, assim, a existência de interatividade, interconexão e inter-relação entre homens, informações e máquinas. A comunicação dominada pelas tecnologias digitais tornou possível a emergência da expressão Cultura Digital porque se trata de algo que nos envolve como a atmosfera, algo no qual participamos como produtores, consumidores, disseminadores e que, por isso, tem integrado a vida cotidiana, invadido as casas e interferido nas relações que estabelecemos com o mundo, tanto material quanto simbólico, que nos rodeia. A Cultura Digital poderia ser pensada como a própria representação de uma fase contemporânea das tecnologias de comunicação, que segue a cultura impressa do século XIX e a cultura eletrônica do final do século XX.

Ao pensar em Cultura Digital, se reflete sobre uma forma de produção, sobre os caminhos nos quais o digital tem sido filiado a certos significados culturais. Quer dizer, para que se possa pensar sobre o conjunto de práticas que envolvem os sujeitos e as tecnologias digitais, é preciso dar a elas significados. Assim, muitos teóricos têm afirmado que todas as práticas sociais são práticas de significação e, por isso, seriam "fundamentalmente culturais" (DU GAY, 1997, p.2). Além disso, dentro dessa discussão, cabe recorrer à ideia central de Williams (1975) de que "a cultura é material", ou seja, a cultura não é simplesmente a maneira como vivemos nossas vidas, senão a própria vida. Deste modo, as Novas Tecnologias de Comunicação e Informação não só incitam as formas pelas quais enxergamos e experimentamos o mundo, mas produzem e são os próprios produtos da sociedade em que vivemos.

Rev. Cad.Comun, Santa Maria, v.20,n.1, art 1, p.1 de 24, jan/abr.2016 


\section{CONSIDERAÇÕES}

Com o reconhecimento da relevância que as tecnologias digitais apresentam na sociedade contemporânea, compreende-se que um conjunto de elementos atrelados ao digital, incluindo os sites pessoais ou institucionais, as redes sociais, os artefatos digitais, entre muitos outros, e todos os tipos de relações que os sujeitos mantêm, compõem parte de um emaranhado de conceitos e ideias que ajudam a produzir a Cultura Digital.

Este é um momento na história em que as tecnologias digitais já não podem ser analisadas apenas enquanto ferramentas, mas como participantes ativas em nossa cultura. A necessidade de problematizar é urgente, especialmente porque as próprias tecnologias digitais estão cada vez mais invisíveis e se tornando parte integrada do tecido social. Além disso, as tecnologias digitais, de alguma forma, também têm alterado os modos de vida e os diversos modelos de negócios, como o da música, do entretenimento, do comércio, da educação. Os blogs, as redes sociais como Facebook e Twitter, os milhares de aplicativos para smartphones e tablets, os canais como YouTube e a enciclopédia online Wikipédia, as plataformas e modalidades de educação à distância, entre inúmeros outros espaços, artefatos e dispositivos ligados ao universo digital, estimulam outras formas de compreender e de se relacionar com o mundo.

O complexo de elementos não pode ser visto apenas como ferramentas, empresas, produtos e serviços postos em circulação e operação, mas como parte de uma rede que acompanha a humanidade e que age como instrumento da memória, da história, da política, da economia, da educação. Contudo, é preciso compreender que o que a revolução tecnológica digital introduz na vida dos sujeitos não é simplesmente uma quantidade inusitada de máquinas eletrônicas e móveis, mas relações entre processos simbólicos e culturais.

Rev. Cad.Comun, Santa Maria, v.20,n.1, art 1, p.1 de 24, jan/abr.2016 
CADERNOS DE COMUNICAÇÃO

UNIVERSIDADE FEDERAL DE SANTA MARIA

REFERÊNCIAS

BAUMAN, Zygmunt. Modernidade líquida. Trad. Plínio Dentzien. Rio de Janeiro: Zahar, 2001.

CASTELLS, Manuel. A Sociedade em Rede, v. 1. Trad. Roneide Venâncio e Jussara Simões. São Paulo: Paz e Terra, 1999.

DU GAY, Paul. Doing cultural studies: the story of the Sony walkman. (Praticando estudos culturais: a história do walkman da Sony). Trad. Leandro Guimarães, Marília Braun e Maria Isabel Bujes. London: Sage Publications/ The Open University, 1997.

GERE, Richard. Digital Culture. London: Reaktion Books, 2008.

LEMOS, André. Cibercultura: tecnologia e vida social na cultura contemporânea. Porto Alegre: Sulina, 2003.

LEMOS, André. Cibercultura como território recombinante. In TRIVINHO, E., CAZELOTO, E. (Ed.), A cibercultura e seu espelho: campo de conhecimento emergente e nova vivência humana na era da imersão interativa. São Paulo: ABCiber, Instituto Itaú Cultural, 38-46, 2009. Disponível em: http://abciber.org/publicacoes/livro1/a_cibercultura_e_seu_espelho.pdf.

LÉVY, Pierre. Cibercultura. Trad. Carlos Irineu da Costa. São Paulo: Editora 34, 1999.

LISTER, Martin; DOVEY, Jon; GIDDINGS, Seth; GRANT, Iain; KELLY, Kieran. New Media: a critical introduction. 2. ed. New York: Routledge, 2009.

MCLUHAN, Marshall. Os meios de comunicação como extensões do homem. Trad. Décio Pignatari. São Paulo: Cultrix, 1970.

WILLIAMS, Raymond. Cultura e Sociedade: 1780-1950. Trad. de Leônidas H. B. Hegenberg, Octanny Silveira da Mota e Anísio Teixeira. São Paulo: Ed. Nacional, 1969.

WILLIAMS, Raymond. Technology and Cultural Form. $1^{\circ}$ ed. Londres: Shocker Books, 1975 .

Rev. Cad.Comun, Santa Maria, v.20,n.1, art 1, p.1 de 24, jan/abr.2016 


\section{Sandro Faccin Bortolazzo}

Bacharel em Comunicação Social/Jornalismo pela PUCRS. Mestre em Educação pela ULBRA na linha de pesquisa Estudos Culturais e Educação. Doutor em Educação pela UFRGS na mesma linha de pesquisa. Meus interesses de pesquisa abrangem novas tecnologias de informação e comunicação, geração digital, cultura digital, juventude, contemporaneidade e consumo.

RECEBIDO EM: 08/02/2016

APROVADO PARA PUBLICAÇÃO: 18/03/2016 